\title{
Characteristics of the Coal Fines Produced from Low-Rank Coal Reservoirs and Their Wettability and Settleability in the Binchang Area, South Ordos Basin, China
}

\author{
Yue Chen ${ }^{(D,},{ }^{1,2}$ Zhuoyuan Ma, ${ }^{1}$ Dongmin Ma, ${ }^{1,2}$ Zhicang Zhang, ${ }^{3}$ Weibo $\mathrm{Li}^{4}{ }^{4}$ Fu Yang, \\ Yusong Ji, ${ }^{1}$ and Tao Peng ${ }^{1}$ \\ ${ }^{1}$ College of Geology and Environment, Xi'an University of Science and Technology, Xi'an 710054, China \\ ${ }^{2}$ Key Laboratory of Coal Resources Exploration and Comprehensive Utilization, Ministry of Natural Resources, Xi'an 710021, China \\ ${ }^{3}$ Shaanxi Coalbed Methane Development Co., Ltd, Xi'an 710119, China \\ ${ }^{4}$ Shaanxi Geological Science and Technology Center, Xi'an 710054, China
}

Correspondence should be addressed to Yue Chen; cyxust@126.com

Received 25 February 2021; Revised 18 March 2021; Accepted 25 March 2021; Published 5 April 2021

Academic Editor: Yanjun Meng

Copyright (C) 2021 Yue Chen et al. This is an open access article distributed under the Creative Commons Attribution License, which permits unrestricted use, distribution, and reproduction in any medium, provided the original work is properly cited.

\begin{abstract}
By using proximate analysis, X-ray diffraction mineral analysis, scanning electron microscope, contact angle measurement, and settlement simulation experiment, the coal fines produced from the coalbed methane wells of Binchang area were used to study the characteristics including particle size distribution, composition, morphology, wettability, and settleability. The results show that the particle size of coal fines produced from coalbed methane wells are mainly $>20$ mesh, ranging of $1-400 \mu \mathrm{m}$, and the particle size distribution curve is mainly dominated by the main-secondary bimodal type, with the main peak of $30-300 \mu \mathrm{m}$. The particle size from large to small is drill cutting coal fines, flowback coal fines, bailing coal fines, and pipeline filter coal fines. In terms of ash content, coal fines are higher than coal seam, and drilling cuttings are higher than bailing coal fines, while the fixed carbon content of the former is lower than that of the latter. The minerals of coal fines are mainly kaolinite, illite, quartz, and other 6 minerals, and the mineral types of drilling coal fines are the most abundant, while the bailing coal fines only contain illite and quartz. The roundness of coal fine particles ranges from excellent to poor in the order of bailing coal fines, pipeline filter coal fines, flowback coal fines, and drilling cuttings. However, the sorting of drilling cuttings is excellent, and the particle edges are straight, neat, and smooth, while the sorting of bailing coal fines is poor, and the particle edges are curved, uneven, and rough. The contact angles of coal fines are $40.25^{\circ}-69.5^{\circ}$, indicating hydrophilous. The wettability of bailing coal fines is better than that of drilling cuttings. The particle size has a negative correlation with the wettability effect. The more obvious the modification effect of positive wetting agent is, the worse the modification effect of negative wetting agent is. The modification of surfactant has nothing to do with the particle size of the coal fines, but is closely related to organic components and minerals. The larger the coal particle size, the higher the settling rate, and the higher the ash content and the lower the fixed carbon content, the faster the settling rate. With the dividing point 150 mesh, the settling rate of large particles is mainly affected by particle size, while that of small particles is affected by the composition.
\end{abstract}

\section{Introduction}

Coal has the characteristics of low compressive strength, small Young's modulus, small Poisson's ratio, fragile, poor cementation, and easy to collapse. Therefore, coal fines are generally produced in the process of coalbed methane drainage, which blocks pore channels and damages the permeabil- ity of the coal seam, which in turn affects the pressure reduction effect of the coal seam [1-6]. According to the generation mechanism of coal fines, coal fines are divided into primary and secondary coal fines. Primary coal fines refer to the coal fines that have always existed in the coal reservoir before the development of coalbed methane during the evolution of the reservoir and are produced under the effects of 
coalification and structural deformation. This part of coal fines mainly exists in fault planes, interlayer sliding planes, and pores in coal [7-9]. Secondary coal fines refer to coal fines produced during the development of coalbed methane, which are divided into two types. One type of coal fines is formed during the compression, deformation, and crushing of coal and rock and is mostly produced during drilling, completion, and fracturing. The other type is caused by factors such as hydrodynamic denudation, coal destruction, and mechanical differences in different microscopic coal and rock components. This type of coal fines has a small particle size and is mostly produced in the drainage and gas recovery process of coalbed methane (CBM) wells [10-12]. The produced coal fines move into the wellbore along with the flow of gas and water, blocking the wellbore and hindering drainage. At the same time, the plunger and the pump are worn out, and the pump stuck or buried in the serious case, which seriously threatens the long-term and stable drainage process of the CBM well $[2,13-16]$.

At present, the researches on coal fines in CBM development mainly focus on three aspects, i.e., characteristics and causes of coal fines, gas and water transport and the rule of coal fine production in drainage and production process, and coal fine prevention and control technology [17-21]. According to the mechanism of coal fine production, it can be divided into three genetic types: inherent, produced by mechanical failure, and produced by stress failure. The nature of coal seam itself is the material basis of coal powder production, including coal rock, coal quality, and coal body structure; also, engineering is the inducing factor of coal fine production, such as drilling, fracturing, and drainage [22-25]. The rule of coal fine production in the process of discharge and production mainly focuses on the rule of coal fine production in each production stage of the gas well, the migration of multiphase flow of coal fines, the rule of settlement and its restricting factors, and the simulation of the rule of coal production driven by gas and water in coal sample [26-32]. The coal fine prevention and control technology mainly include regulation and control of discharge and production system, coal fine control equipment, and additive injection [33-37]. To avoid coalbed methane production problems caused by coal fine production, researchers have used transmission light microscopy, reflection polarization optical microscopy, laser particle size analysis, X-ray diffraction, scanning electron microscopy, and other experimental methods to study the morphological characteristics of coal at different discharge stages, particle size distribution, and material composition [38]. Guo et al. [39] conducted a laboratory investigation on the production of coal fines and believed that the main component of the coal fines produced was clay minerals. Wei et al. [40] believed that the migration law of coal fines is affected by the particle size of coal fines and the content of inorganic minerals. Liu et al. [41] explored change of fuel microstructure during high-temperature coke combustion was analyzed, and the reaction process and particle change behavior were revealed. Kuang et al. [42] analyzed the flow and chemical reaction characteristics at different oxygen concentrations and inlet velocities, and the temperateness was determined. However, there are relatively few studies on the wettability of coal fines. After the activator used in the production process penetrates into the coalbed methane reservoir, it may cause changes in the wettability of the coal rock surface and then changing the wettability and sedimentation of the coal fines. This changes the movement and migration of coal fines in gas and water in the pores and affects the productivity of coalbed methane [43-46].

However, previous studies mainly focused on the Qinshui Basin and the eastern margin of Ordos Basin in China and other middle-high coal-rank areas, while less involved low-rank coal reservoirs. Based on the actual development of low-rank coalbed methane in the Binchang area of the southern Ordos Basin, the author conducts a comprehensive study on the particle size distribution, material composition, morphological characteristics, wettability, and subsidence of coal fines produced from coalbed methane wells. It is hoped to provide a reference for formulating reasonable coal fine control measures to avoid the adverse effects of coal fines on production.

\section{Geological Settings}

Huanglong Jurassic coalfield is located in Shaanxi Province in the southwest of Ordos Basin, extending to ShaanxiGansu boundary in the north, Longxian county in Baoji in the west, and Huangling to the east. Yan'an formation coal seam outcrops in the south, with a total area of $9300 \mathrm{~km}^{2}$ [47]. It is divided into Yonglong mining area, Binchang mining area, Xunyao mining area, Jiaoping mining area, and Huangling mining area. The tectonic straddles the Weibei fault uplift area and the western margin fold-thrust belt on the southern margin of the Ordos Basin. The NE-trending and EW-trending fold tectonics are mainly developed, and the fault tectonics are less developed and are mainly located in the southeast and southwest margin of the coalfield (Figure 1). The area is rich in coal resources, with coal resources up to $6.7 \times 10^{9} \mathrm{t}$, and the recoverable coal seam is mainly Jurassic Yan'an formation coal seam, mainly lowrank weakly caking coal and long flame coal and gas coal $[48,49]$. The Dafosi minefield is located in the Binchang mining area in the middle of the coalfield. The internal structure is relatively simple, fault is undeveloped, strata are gentle, and the dip angle is generally less than $5^{\circ}$. The main mining coal seam is Yan'an formation, and the coal seam has a high gas content, ranging from 1.44 to $2.56 \mathrm{~m}^{3}$. The prospect of coalbed methane development is good. The exploration and development of coalbed methane in Dafosi minefield began in 2009. By the end of 2019, more than 40 coalbed methane drills have been carried out, mainly horizontal wells, and the maximum gas production per well is more than $3 \times 10^{4} \mathrm{~m}^{3} / \mathrm{d}$, which has achieved good gas production results [50].

\section{Samples and Methods}

3.1. Samples. The experimental samples are collected from the coalbed methane well and the coal fines produced by 


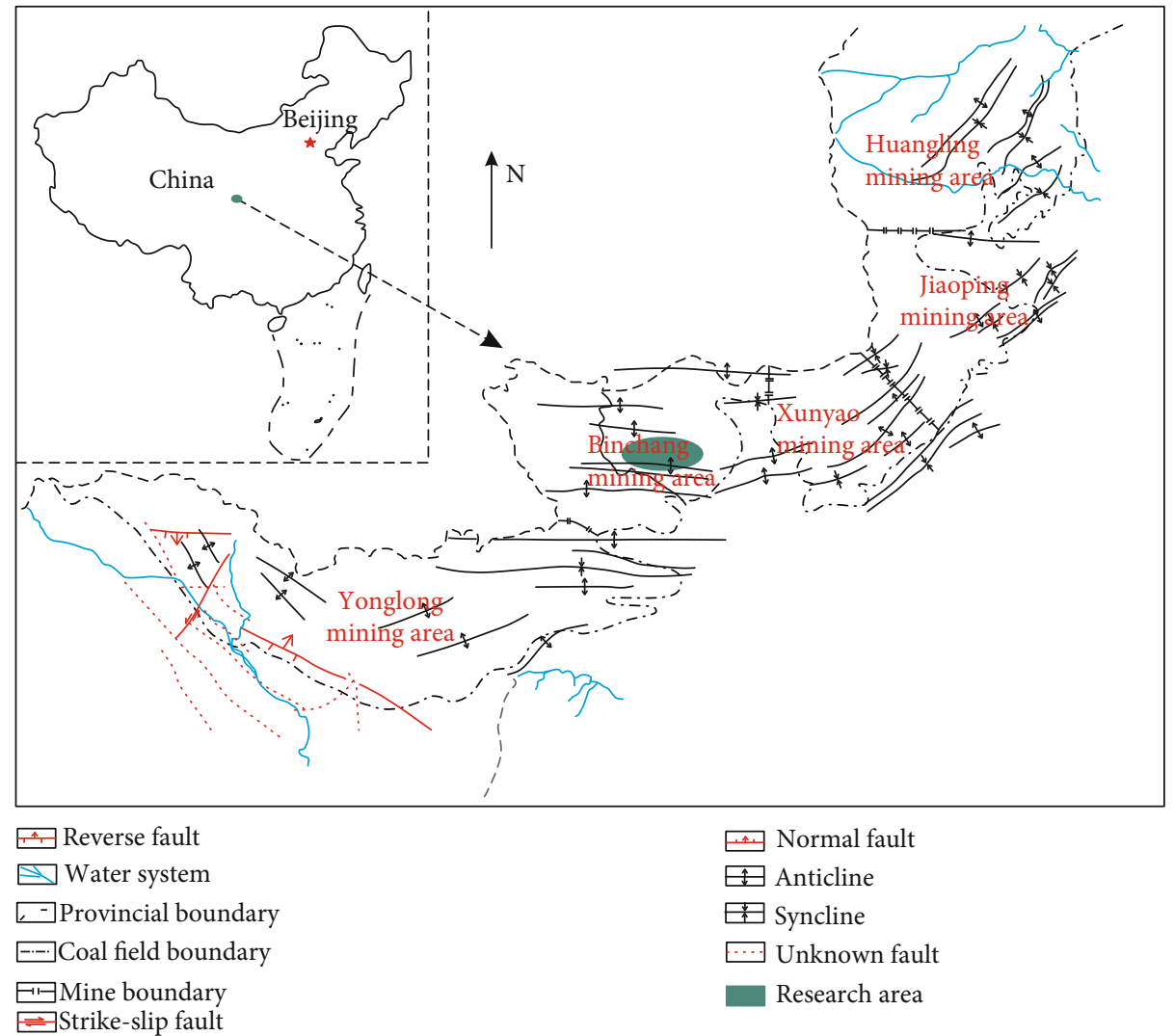

Figure 1: Tectonic outline of the Huanglong coalfield.

TABLE 1: Basic information of coal fine sample collection.

\begin{tabular}{lccc}
\hline Serial number & Sample number & Collection location & Coal fine type \\
\hline 1 & ZX & DFS-143 well & Drill cutting coal fines \\
2 & LS & DFS-68 well & Bailing coal fines \\
3 & FP & DFS-143 well & Flowback coal fines \\
4 & LS-1 & Upper section of DFS-69 well & Bailing coal fines \\
5 & LS-2 & Middle section of DFS-69 well & Bailing coal fines \\
6 & LS-3 & DFS-69 downhole section & Bailing coal fines \\
7 & LX & Gathering pipeline filter element & $/$ \\
\hline
\end{tabular}

the gathering pipeline in the Dafosi minefield of Binchang mining area, and the source coal seam is the Yan'an formation coal seam of Jurassic. The specific information is shown in Table 1. The types of coal fines include drilling cuttings in the drilling process of coalbed methane wells (ZX), coal fines discharge in the initial stage of production (FP), bailing coal fines in the process of workover (LS), and coal fines on the filter element of coalbed methane gathering and transportation pipeline (LX). After collecting the coal fine samples on the spot, the drilling cutting coal fines, the flowback coal fines, and the pipeline filter coal fines are directly dried, screened, and processed according to the test requirements, and the bailing coal fine samples are precipitated, filtered, stirred, screened, and dried. Prepare the required experimental samples according to the test requirements. The particle size of coal fines is screened with three kinds of sieves: 20 mesh, 80 mesh, and 150 mesh. According to the particle size, the coal fines are divided into four particle size ranges: $<20$ mesh (>830 $\mu \mathrm{m}), 20-80$ mesh $(180-830 \mu \mathrm{m}), 80-150$ mesh (106$180 \mu \mathrm{m})$, and more than 150 mesh $(<106 \mu \mathrm{m})$.

3.2. Experimental Methods. The coal quality analysis was conducted according to the coal industry standard of the People's Republic of China (GB/T212-2008), and the average value of each sample was taken after 2 samples were tested. Particle size analysis uses sieving weighing method and laser particle size analysis method, in which the advantage of laser particle size analysis is efficient, accurate, and can obtain continuous particle size distribution, but the test particle size range is relatively limited $(0.001-1000 \mu \mathrm{m})$, and particle size $>1 \mathrm{~mm}$ needs to be supplemented by screening weighing method. 


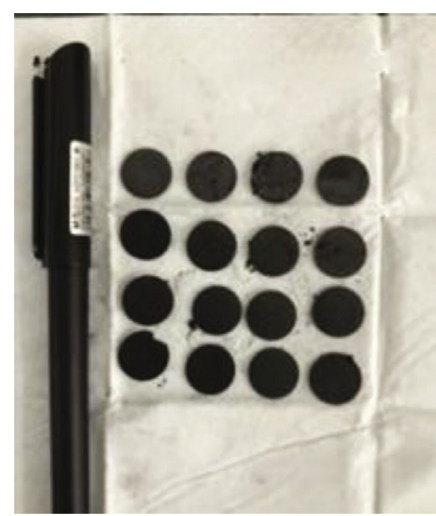

(a)

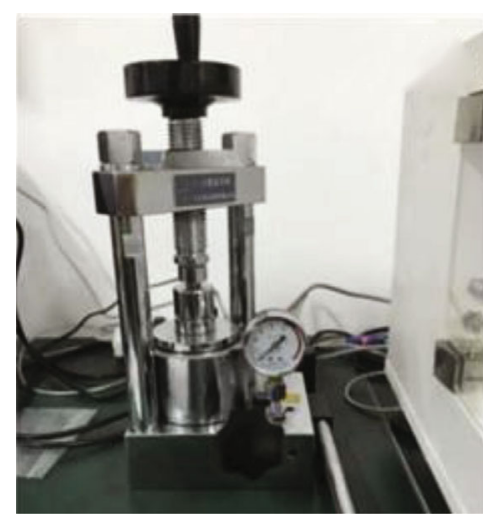

(b)

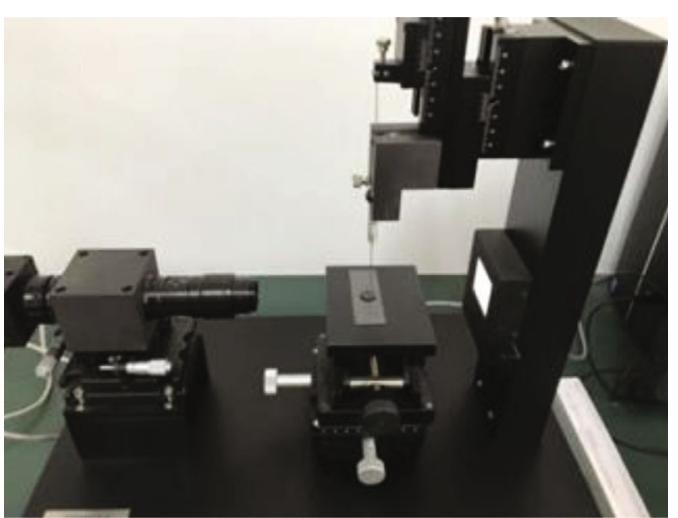

(c)

Figure 2: Sample preparation and measurement of contact angle ((a) pressed coal sheet sample, (b) YP-15 tablet machine, and (c) JC2000 video contact angle measuring instrument).

The contact angle characterization method is used to analyze the wettability of coal fines. Firstly, the coal fine sample is pressed into a round sheet with a diameter of about $2 \mathrm{~cm}$ (Figure 2(a)) with a YP-15 pressing machine (Figure 2(b)). Then, the contact angle is measured by the JC2000 video contact angle measuring instrument (Figure 2(c)). The liquid is distilled water, and each sample is tested in different parts for 3 times, and the average value is taken. Besides, to analyze the effect of different surfactants on the wettability of coal fines, three kinds of surfactant solutions with $2 \%$ volume concentration of 6501 (coconut oil fatty acid diethanolamide) solution, ethylene glycol solution, and clay curing agent solution were tested.

In the coal fine settling experiment, the final settling rate of coal fine particles is studied by tracking the movement process of coal fine particles in a "vertical wellbore" filled with water. Before the start of the experiment, the coal fine sample was fully wetted with water, and the whole process of coal fine particle settling in the field of view (rate measurement section) was recorded with a high-definition digital camera. In the later stage, the length of the scale inside the video tube was measured, combined with the time interval recorded by the stopwatch, and the average settling rate of coal fine settlement was calculated (Figure 3). In the experiment of each sample, 10 representative settling rates of coal fine particles are calculated and the average value is taken.

\section{Results and Discussions}

\subsection{Particle Size Distribution}

4.1.1. Sieve Particle Size. The screening results of drilling cutting coal fines (ZX) and bailing coal fines (LS) show (Figure 4) that the particle size distribution of coal fines is wide, and it is distributed from millimeter to micron. The weight ratios of $<20$ mesh, 20-80 mesh, 8-150 mesh, and $>150$ mesh of drilling cutting coal fines are 3.7\%, $22.22 \%, 66.67 \%$, and $7.41 \%$, and the bailing coal fines are $10.67 \%, 12.67 \%, 66.67 \%$, and $23.33 \%$. The particle size of coal fines is more than 20 mesh microns in general, more than 89 percent. However, the content of coal fines with a particle size above a millimeter is less than $11 \%$. There is a significant difference in particle size between drill cutting coal fines and bailing coal fines. The millimeter grade $(<20$ mesh) coal fines in bailing coal fines are nearly 3 times higher than that of drilling cutting coal fines. The micron particles in the drill cutting coal fines are mainly 20-80 mesh and 80-150 mesh, and the particle size is relatively coarse, especially the 80-150 mesh particles account for $66.67 \%$, while the small size particles $>150$ mesh account for less than $10 \%$. But the bailing coal fines are different, the micron particles are mainly $80-150$ mesh and $>150$ mesh, and the particle size is relatively fine. The particle size of 20-80 mesh is only $12.67 \%$, which is lower than that of drilling cutting coal fines. Therefore, from the point of view of mass proportion, the particle size of drilling cutting coal fines is thicker than that of sand bailing coal fines, and both of them are mainly micron particles of $>20$ mesh.

4.1.2. Laser Particle Size Distribution. To further analyze the characteristics of the detailed particle size distribution of coal fines below millimeter level, which is dominant in coal fines, seven coal fines samples are tested by laser particle size analyzer, and the particle size distribution curves of each sample are shown in Figures 5 and 6 . The particle size distribution curve of coal fines is mainly bimodal, one primary and one secondary (Figures 5(a)-5(c)).

The dividing line between the secondary peak and the main peak of pipeline filter coal fines (LX) element is not obvious (Figure 5(d)), which may be related to the difference of particle size of organics and inorganics in coal fines. Because the bailing coal fines are screened by groundwater flow, its mineral content is higher and the bimodal characteristics are more obvious, while the main components of core pipeline filter coal fines are organic, and the secondary peaks are undeveloped. The particle sizes of all kinds of coal fines are between $1 \mu \mathrm{m}$ and $1000 \mu \mathrm{m}$, mainly between $10 \mu \mathrm{m}$ and $500 \mu \mathrm{m}$, which are consistent with the screening results, and there are few coal fine particles with particle sizes less than $10 \mu \mathrm{m}$ and more than $400 \mu \mathrm{m}$. The former accounts for about $10 \%$, while the latter generally accounts for less than $10 \%$. The D10 value of the particle size cumulative 


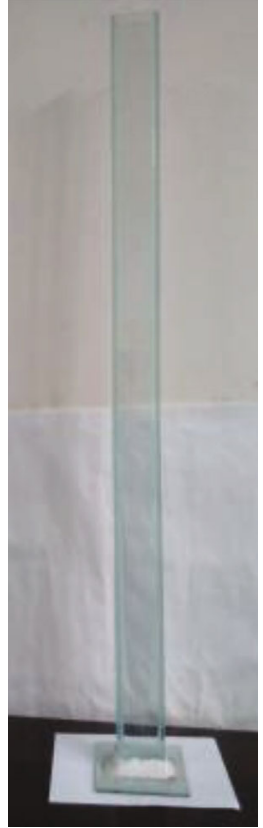

(a) Cylindrical transparent utensils

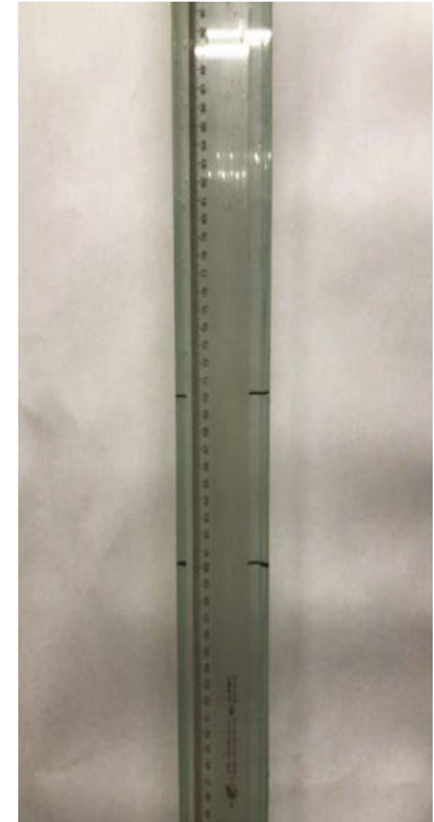

(b) Calibration distance of camera plastic ruler

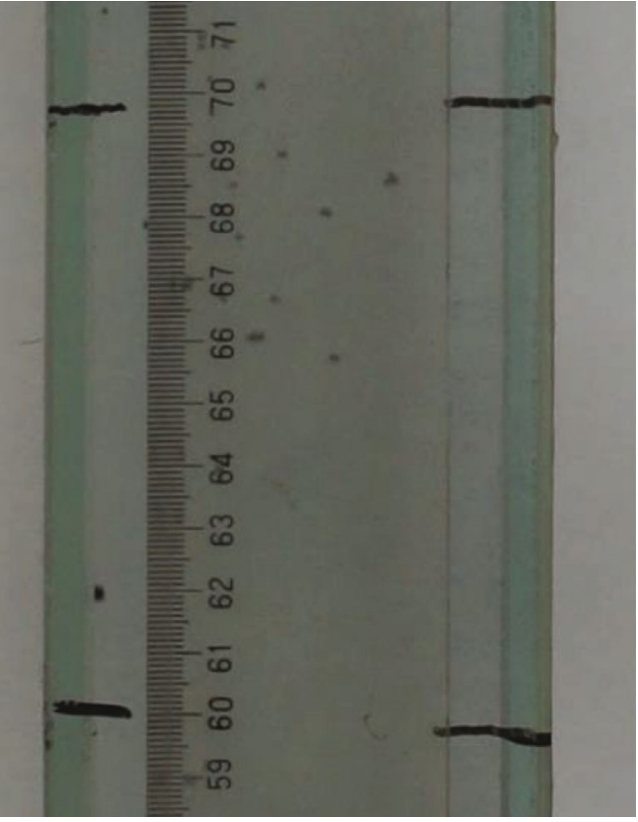

(c) Coal fine particles pass through the field of view

Figure 3: Settling experiment of coal fines.

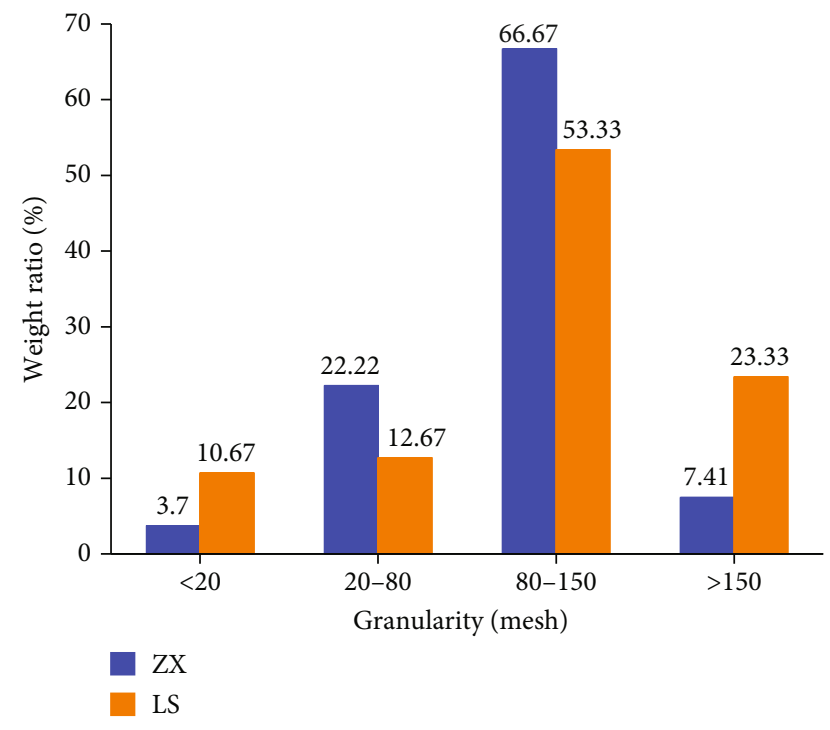

FIgURE 4: Particle size distribution of coal fines through sieving.

distribution curve is between $3.85 \mu \mathrm{m}$ and $12.32 \mu \mathrm{m}$, while the D90 value is between $75.05 \mu \mathrm{m}$ and $412.50 \mu \mathrm{m}$. Based on the comparative analysis of the particle size distribution of all kinds of coal fines, it is found that the particle size of drilling cutting coal fines is the thickest, and the D50 and D90 values of particle size distribution are $162.30 \mu \mathrm{m}$ and $412.50 \mu \mathrm{m}$, respectively. The particle size of the main peak is about $300 \mu \mathrm{m}$. The second is the flowback coal fines at the initial stage of gas well production. The main peak particle size of the particle size distribution curve is about $100 \mu \mathrm{m}$, and the D50 and D90 values are $82.25 \mu \mathrm{m}$ and $218.80 \mu \mathrm{m}$, respectively, which are smaller than those of drilling cutting coal fines, and the overall particle size is generally less than $200 \mu \mathrm{m}$. The particle size of bailing coal fines is finer, and the particle size of the main peak is about $100 \mu \mathrm{m}$, which is close to that of coal fines, but the values of D50 and D90 are obviously lower, which are $44.71 \mu \mathrm{m}$ and $194.00 \mu \mathrm{m}$, respectively, because the second peak is more developed. The coal fine particle size of the pipeline filter is the finest; the peak particle size curve is about $30 \mu \mathrm{m}$, and there is only one main peak, and the secondary peak is not developed. The values of D50 and D90 are $22.72 \mu \mathrm{m}$ and $75.06 \mu \mathrm{m}$, respectively, and the particle size is the smallest among the four coal fine samples. Therefore, in terms of the overall particle size of pulverized fines, from large to small is drill cutting coal fines, flowback coal fines, bailing coal fines, and pipeline filter coal fines. At the same time, it shows that there may be differences in the genesis of different types of coal fines. It is speculated that drill cutting coal fines and flowback coal fines are mainly formed by mechanical crushing in engineering, and flowback coal fines are mainly caused by the transport and production of coal fines left in the wellbore during drilling. The bailing coal fines and the pipeline filter coal fines are the coal fines formed by the primary coal fines in the coal reservoir and the particles on the pore fracture surface with the flow of gas and water and then transported to the wellbore by gas and water, and the larger coal fine particles subside, and the small particles are carried to the ground by gas and water to produce. Besides, due to differences in particle size, material composition, and wettability, the subsidence speed of each particle size of coal fines in the wellbore is different, which is confirmed by the subsidence experimental results later.

By comparing and analyzing the particle size distribution of bailing coal fines at different positions in the same 


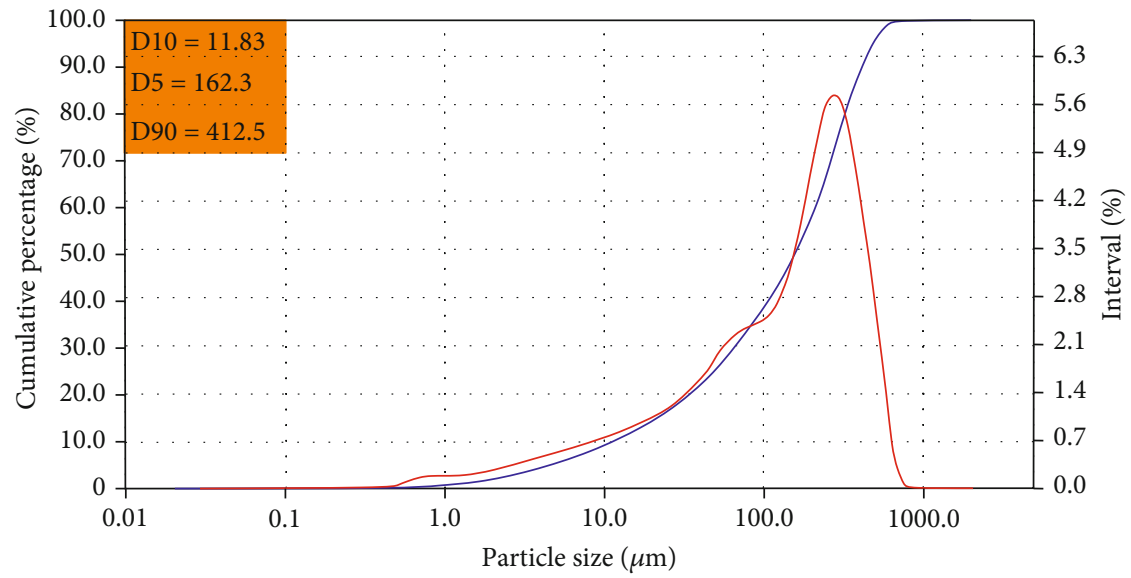

- Cumulative percentage (\%)

_ Interval (\%)

(a)

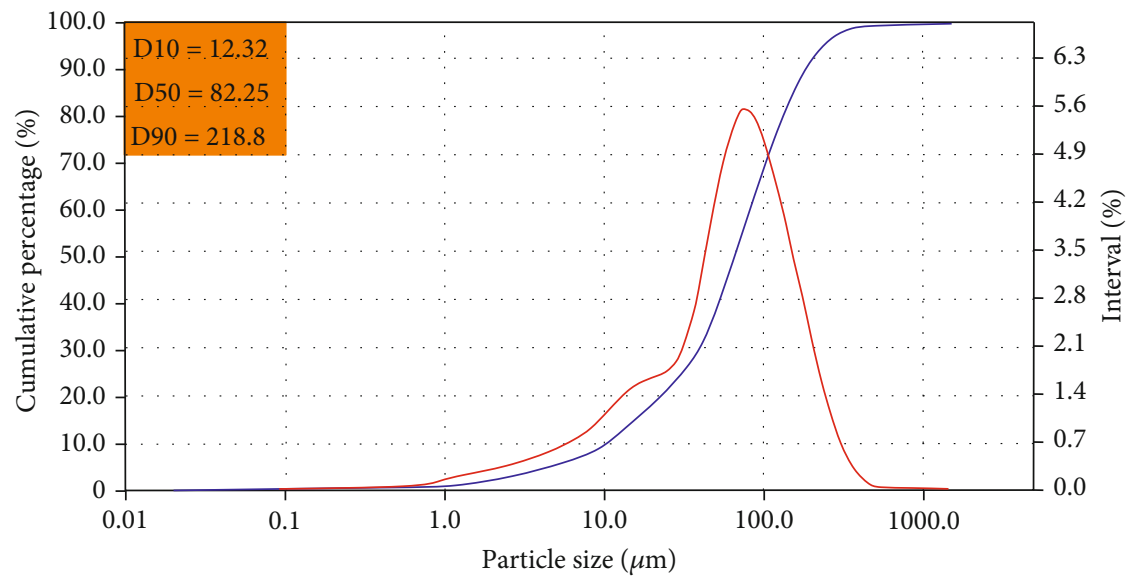

— Cumulative percentage (\%)

— Interval (\%)

(b)

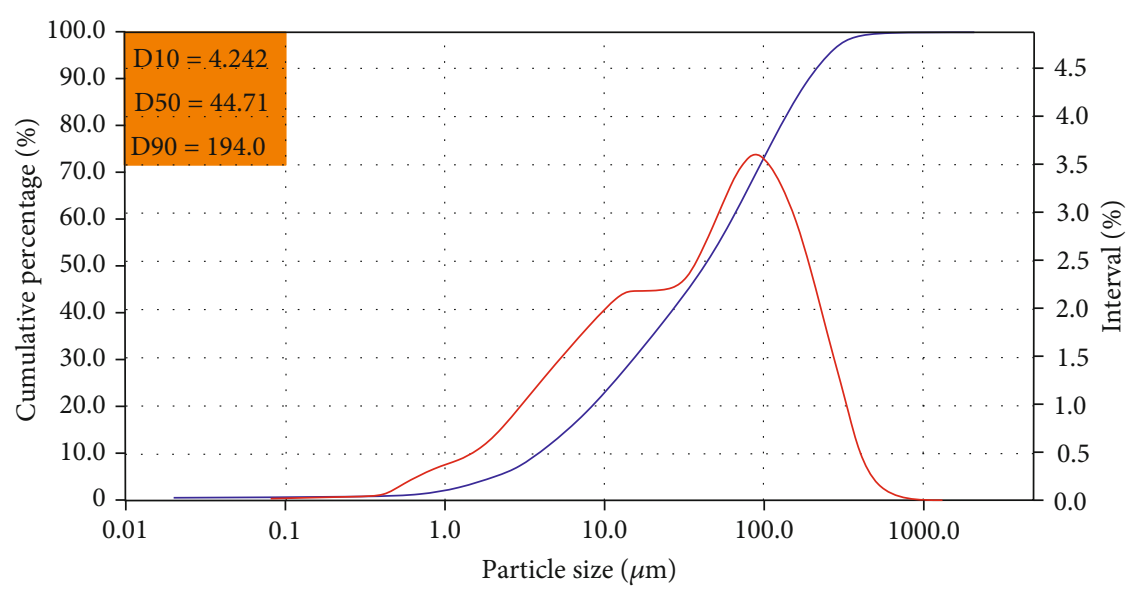

- Cumulative percentage (\%)

_ Interval (\%)

(c)

Figure 5: Continued. 


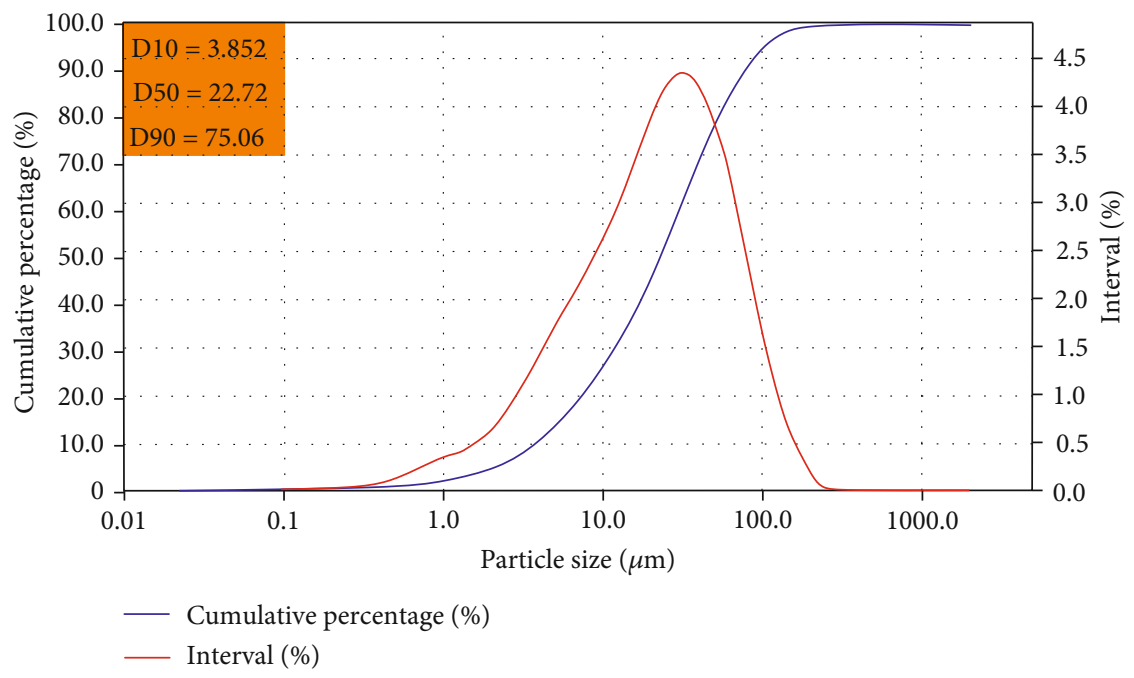

(d)

Figure 5: Particle size distribution curves of different coal fine types ((a) ZX, (b) FP, (c) LS, and (d) LX).

wellbore, it is found that the particle size distribution of bailing coal fines (LS-3) is conspicuous different (Figure 6). The particle size of bailing coal fines (D50) at the bottom is the thickest, and the D50 and D90 values of the main peak and peak diameter are $21.88 \mu \mathrm{m}$ and $175.30 \mu \mathrm{m}$, respectively (Figure 6(c)). The bailing coal fines (LS-1) located in the uppermost part have the finest particle size, and the D50 and D90 values of the main peak are about $30 \mu \mathrm{m}$, $14.77 \mu \mathrm{m}$, and $63.10 \mu \mathrm{m}$, respectively (Figure 6(a)). On the other hand, the particle size of the bailing coal fines located in the middle is between the two, and the main peak particle size is about $90 \mu \mathrm{m}$, and D50 and D90 are $77.72 \mu \mathrm{m}$ and $252.40 \mu \mathrm{m}$, respectively (Figure 6(b)).

Therefore, in terms of particle size, the order of bailing coal fines from coarse to fine is LS-3, LS-2, LS-1, that is, lower section $>$ middle section $>$ upper section. Moreover, if the secondary peak of the segmented bailing coal fine particle size curve at $1 \mu \mathrm{m}$ is ignored, it is in good agreement with the particle size curve of LS, the secondary peak of LS is the same as the main peak of LS-1, and the particle size of LS is between the main peak of LS-2 and LS-3, which shows that the subsidence rate of coal fines in the wellbore is closely related to the particle size, and the sedimentation process plays a certain role in sorting.

\subsection{Material Composition}

4.2.1. Proximate Analysis. To compare the material composition characteristics of different size particles of different types of coal fines, the drilling cutting coal fines and bailing coal fines of four-particle sizes were analyzed in industry, and the results are shown in Figure 7. First of all, the average values of moisture, ash, volatile, and fixed carbon of drill cutting coal fines are $3.34 \%, 26.22 \%, 25.90 \%$, and $42.65 \%$, respectively, and those of bailing coal fines are $4.54 \%$, $15.86 \%, 25.39 \%$, and $57.99 \%$, respectively. There are some differences between them, especially ash and fixed carbon. The ash content of drilling cutting coal fines is higher, while the fixed carbon content of bailing coal fines is higher. This is because the particles of coal seam gangue and surrounding rock of roof and floor are easy to mix into drilling cutting coal fines during drilling, so that the ash content is much higher than the average ash content of this coal seam. On the other hand, the bailing coal fines are mainly formed by the coal reservoir, and its composition is closer to the coal seam itself, but its ash content is still slightly higher than that of the coal seam, because the properties of organic components and inorganic minerals in coal are different, which leads to different particle migration and output capacity. Besides, the transport and separation as well as differential sedimentation of gas flow make the minerals in the bailing coal fines relatively enriched. There is little difference in moisture and volatile content between the two kinds of coal fines, which is close to the average value of coal seam. Comparatively speaking, the moisture content of drilling cutting coal fines is slightly lower than that of bailing coal fines, and the volatile content is slightly higher.

Secondly, there are great differences in the material composition of coal fine particles of different sizes. In terms of ash content, the ash content of particles with drill cutting coal fines $<20$ mesh and $>150$ mesh is particularly high, which is $28.36 \%$ and $29.09 \%$, respectively, while the ash content of particles with 20-80 mesh and 80-150 mesh is slightly lower, which is only $24.91 \%$ and $22.51 \%$. The ash content of bailing coal fines is relatively low, which is $11.05 \%$ and $25.47 \%$, and is closely related to the particle size. The particle size is inversely proportional to the ash content. In terms of moisture, the moisture of 20-80 mesh particles of drill cutting coal fines is the highest, and the overall change is little, and the moisture of each particle diameter of bailing coal fines is the same, about $4.5 \%$. In terms of volatile matter, the volatile content of the particles with drilling cutting coal fines $<20$ mesh is the lowest, and that of 20-80 mesh particles is the highest, while the volatile content of bailing coal fines decreases with the decrease of particle size. 


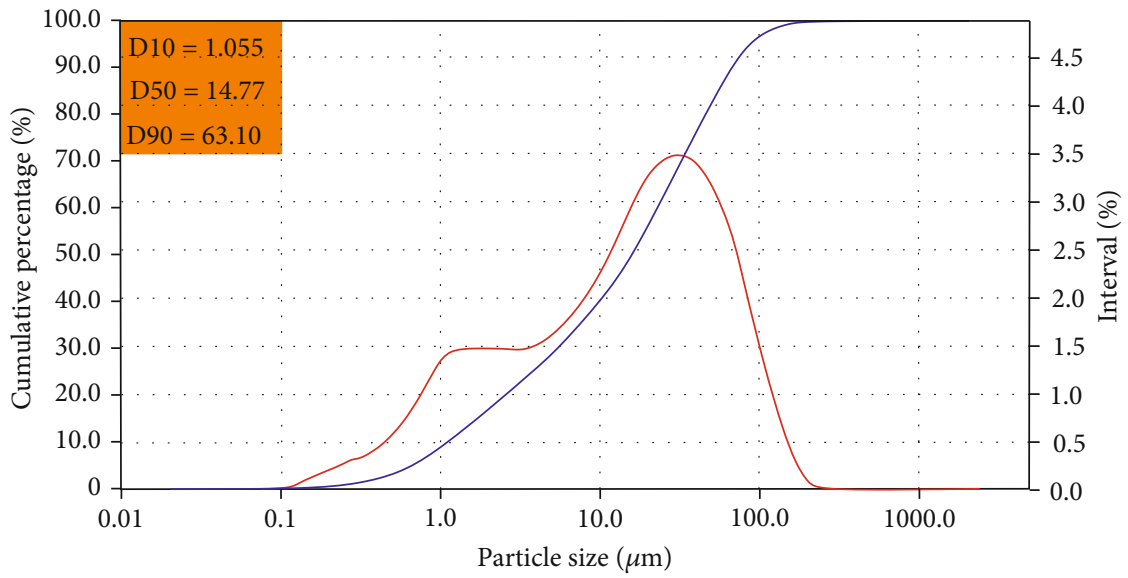

- Cumulative percentage (\%)

— Interval (\%)

(a)

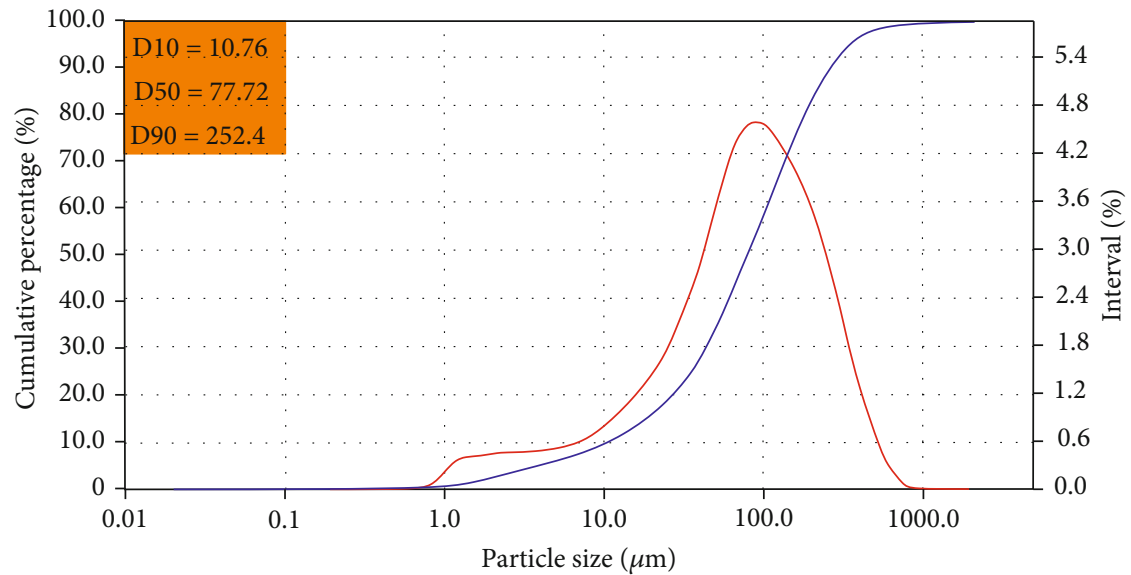

- Cumulative percentage (\%)

— Interval (\%)

(b)

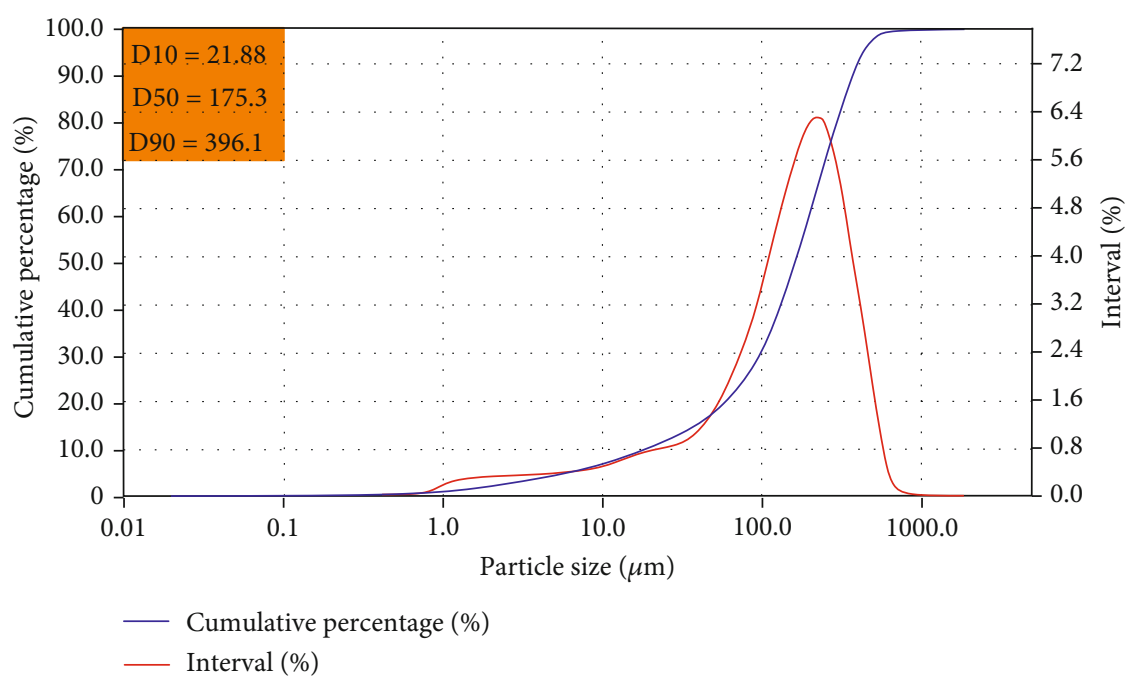

(c)

Figure 6: Particle size distribution curves of the upper, middle, and lower parts of bailing coal fines ((a) LS-1, (b) LS-2, and (c) LS-3). 


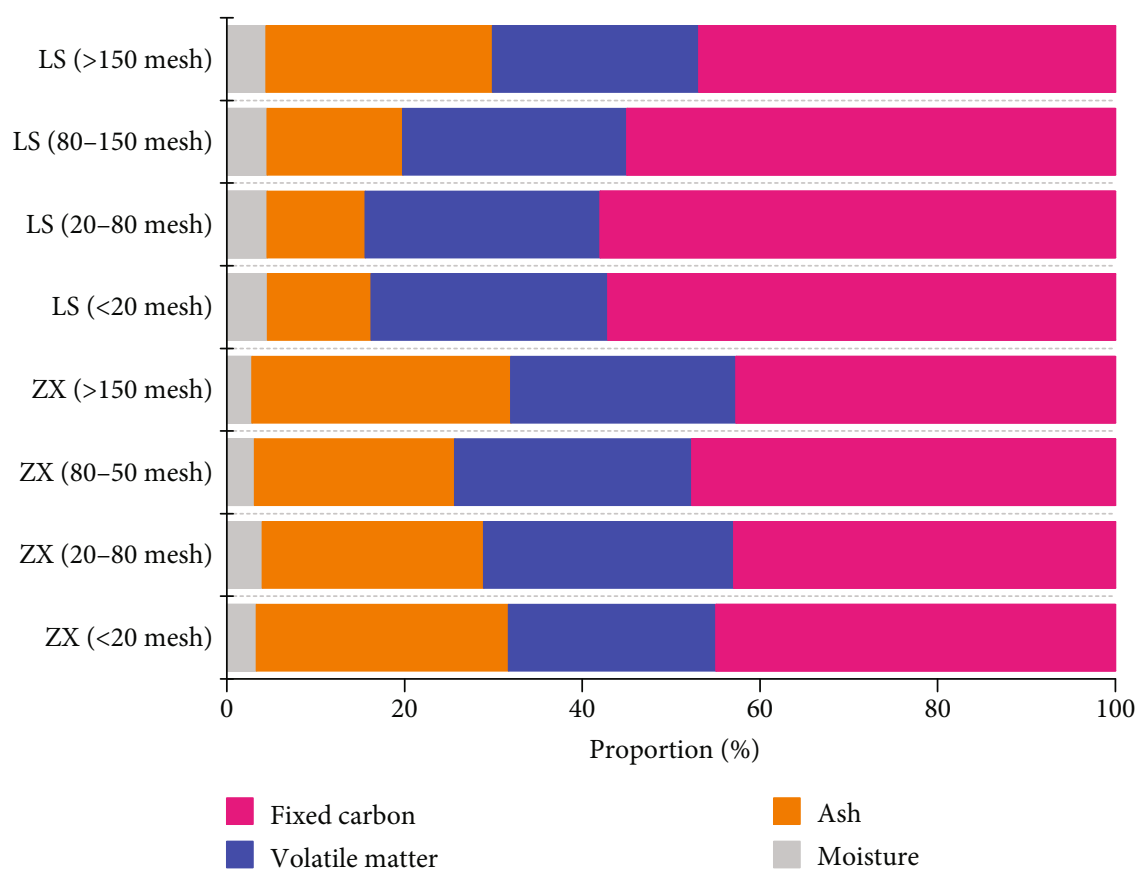

FIGURE 7: Proximate analysis results of drilling cuttings and bailing coal fines.

4.2.2. Mineral. X-ray diffraction mineral analysis is often used to determine the types of minerals in rocks. The X-ray diffraction pattern of coal fines can be interpreted concerning the atlas of mineral thermal analysis, power-crystal analysis, and phase transition [51], as shown in Figure 8. The results show that different types of coal fines contain different kinds of minerals, and the most kinds of minerals are drill cutting coal fines, including kaolinite, illite, anhydrite, quartz, calcite, and magnetite (Figure 8(a)). The high ash content of drill cutting coal fines can confirm each other. The second is flowback coal fines, which mainly contain kaolinite, illite, quartz, calcite, and magnetite (Figure 8(b)), which is similar to drilling cutting coal fines, while magnetite may be formed by wear and tear of metal equipment in drilling engineering. It can be seen that the flowback of coal fines in the initial stage of production of CBM wells mainly comes from the coal fines remaining in the wellbore and the pores of the reservoir, which is formed by drilling, reservoir modification, and other projects that cause the coal to be fractured, which is consistent with the previous understanding. However, the mineral characteristics of bailing coal fines are quite different from the above two, and there are few kinds of minerals, only illite and quartz (Figures $8(\mathrm{c})-8(\mathrm{e}))$. The reason may be that after the formation of coal fines, through the transportation, sorting, and dissolution of groundwater, the soluble minerals such as calcite and anhydrite are dissolved and transported out, resulting in fewer kinds of minerals and relative accumulation of minerals which are difficult to transport or easy to subside. Based on the further analysis of the bailing coal fines at different positions, it is found that there is only one kind of quartz in the upper part of the sample, while illite and quartz are found in the middle and lower sec- tions, which may be related to the subsidence rate and wettability of different minerals in the water.

\subsection{Topographic Characteristics}

4.3.1. Micromorphology. By observing the morphology of fine coal particles under microscope, it is found that the shapes of fine coal particles are various, and the roundness, surface roughness, and edge morphology of coal fine particles are different. The roundness of coal fine particles is divided into four levels: angular, subangular, subcircular, and circular (Figure 9). It is generally believed that the roundness of coal fines is affected by genesis, and that round and subcircular coal fines are mainly caused by erosion in the process of transportation, while angular and subangular coal fines are the result of a brittle failure caused by force. Such as the drilling process, fracturing process and mechanical damage and stress changes caused in the process of drainage and production. Drilling cutting coal fines are mainly subangular, and the flowback coal fines and drilling cutting coal fines have a similar genesis and also have the characteristics of erosion in the process of transportation, so they are mainly subangular and subcircular. On the other hand, the bailing coal fines have experienced long-distance transportation, which is mainly round and subcircular. Because of the small particles, the pipeline filter coal fines suffer a slightly lower degree of erosion in the process of transportation, mainly subcircular. However, the three-dimensional shape of coal fines is mainly short columnar and granular, and flake coal fines are rarely developed, because the coal structure of Dafosi minefield is relatively complete, mainly primary structure and cataclastic structure, and structural coal is not developed. Therefore, the main causes of coal fines are mechanical damage and gas- 


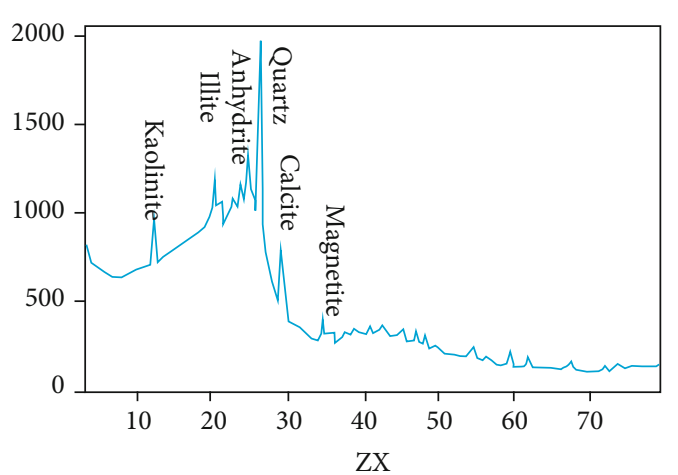

(a) ZX

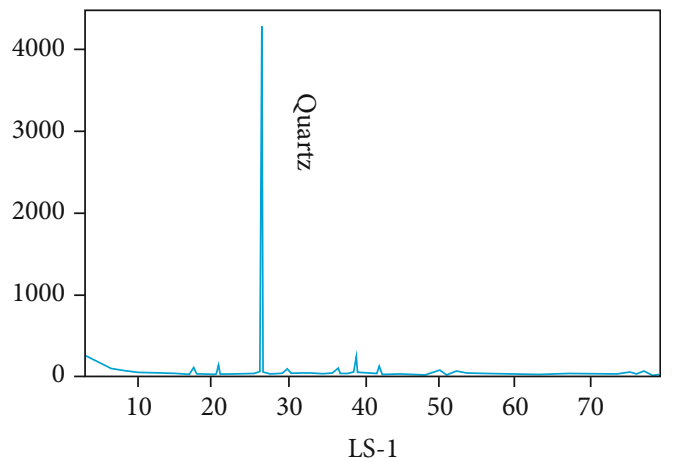

(c) LS-1

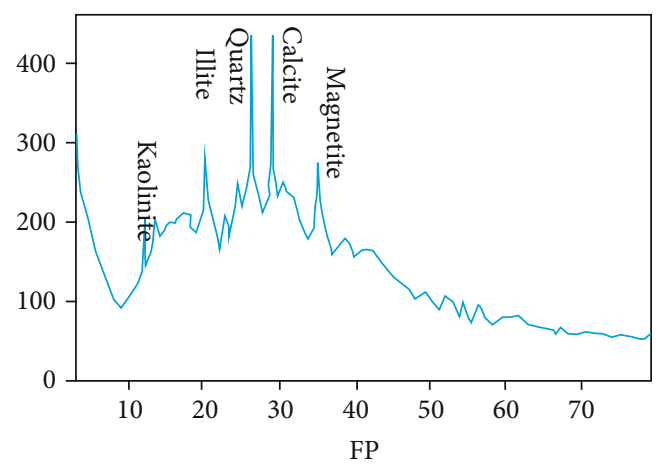

(b) FP

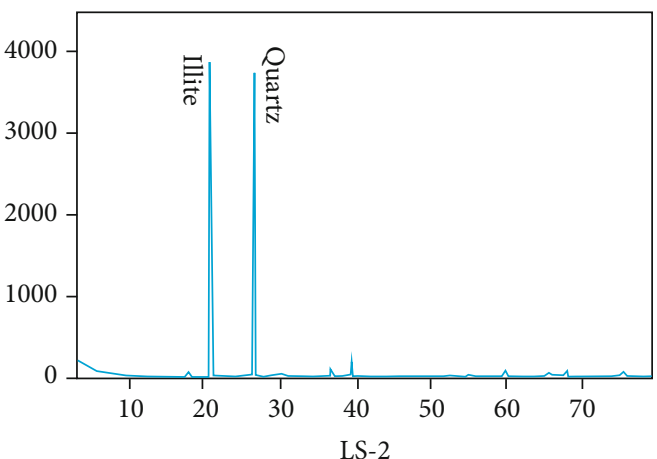

(d) LS-2

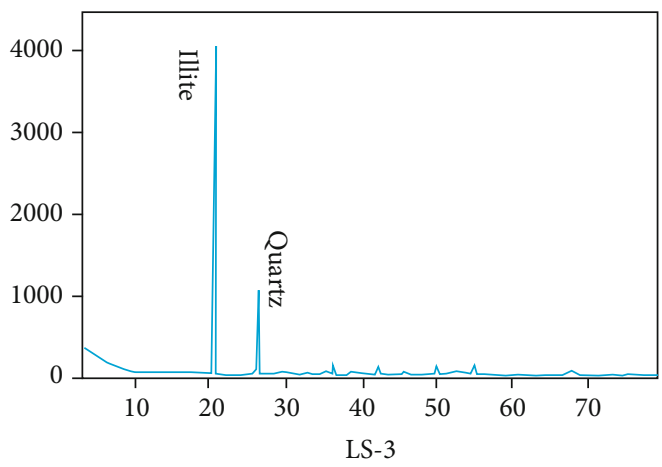

(e) LS-2

Figure 8: X-ray diffraction mineral analysis of different coal fines.

water scouring, and generally, there is no flake exfoliation genesis (mainly for scaly structural coal, mylonite coal, and other structural coal).

4.3.2. SEM Feature. At the same time, drilling cutting coal fines and bailing coal fines also have different morphological characteristics under the scanning electron microscope (SEM). First of all, at the same magnification, the drill cutting coal fine particles are larger and the bailing coal fine particles are smaller (Figure 10), which is consistent with the results of the previous particle size analysis. Secondly, the edge of drilling cutting coal fine particles is relatively straight, neat, and smooth, which accords with the genetic characteristics of rapid mechanical failure, while the edge of bailing coal fines is curved, staggered, and rough, which is mainly controlled by the original particle characteristics and certain transporta- tion and erosion. Thirdly, the size distribution of drilling cutting coal fines is more uniform, the separability is good, and the size distribution of bailing coal fine particles is uneven, especially for coal fine particles less than $10 \mu \mathrm{m}$, which has a great difference in size and poor separability, because it changes with the rate of gas and water products. The particles of different sizes on the pore surface of the coal reservoir are washed off into coal fines and then mixed through transportation and settlement, resulting in uneven particle size and poor sorting.

\subsection{Wettability}

4.4.1. Contact Angles. The contact angles of solid-liquid interface are commonly used to characterize the wettability of solid surface. The smaller the contact angle is, the better the 


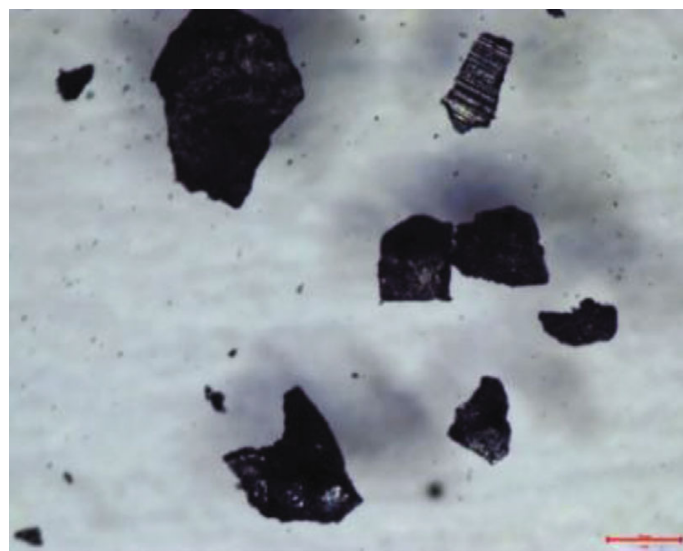

(a) ZX, angular shape

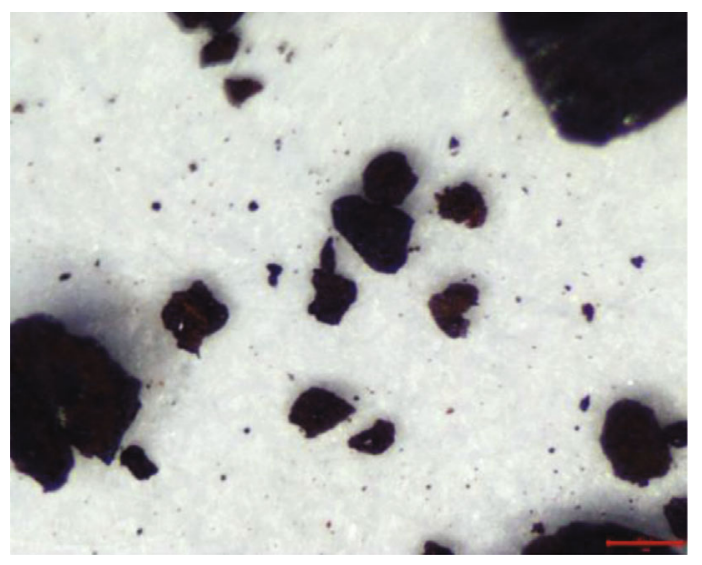

(c) LS, subcircular and circular

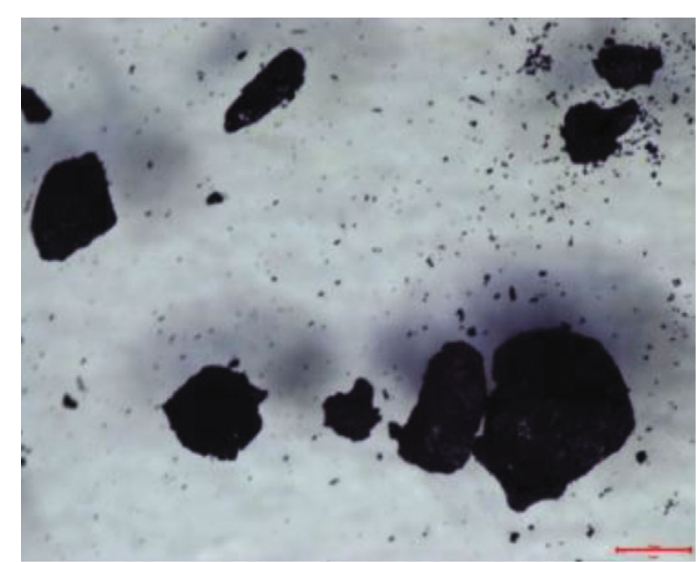

(b) FP, subangular and subcircular

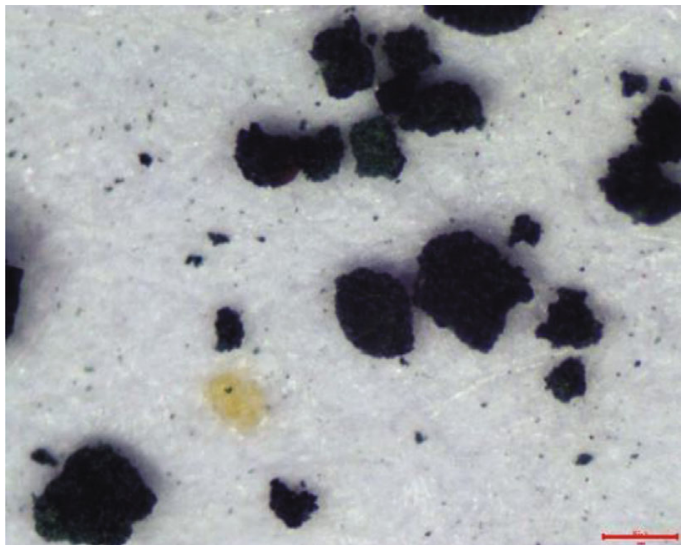

(d) LX, subcircular

Figure 9: Photomicrograph of different types of coal fines.
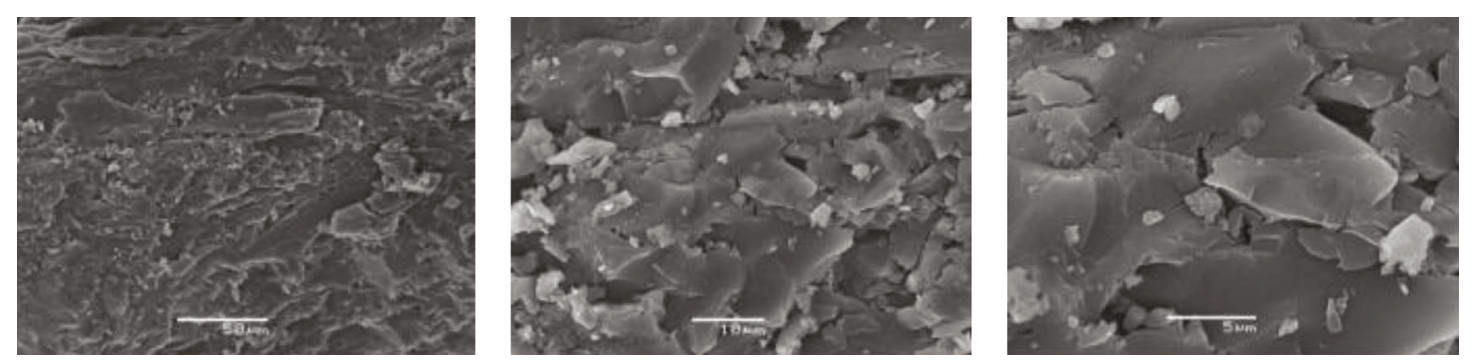

(a) ZX scanning electron microscope photos
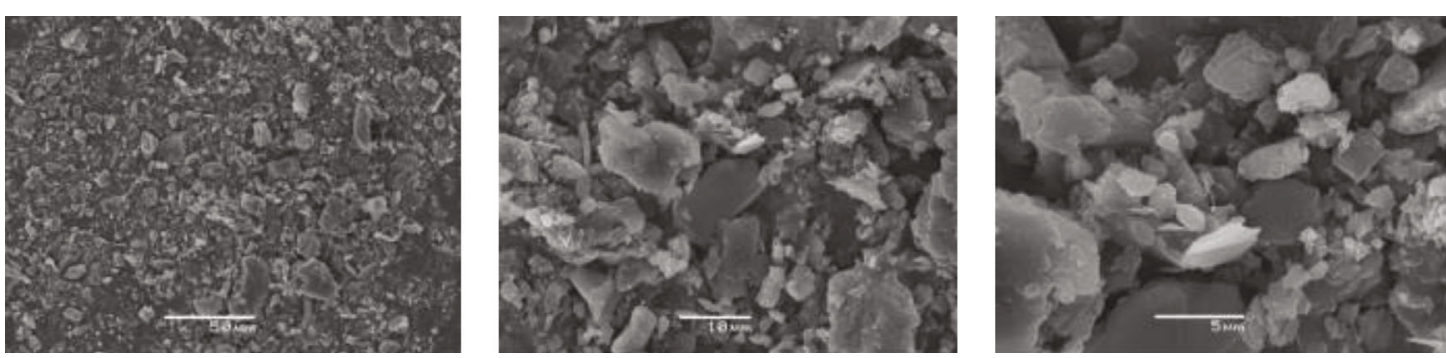

(b) LS scanning electron microscope photos

Figure 10: SEM of different types of coal fines. 


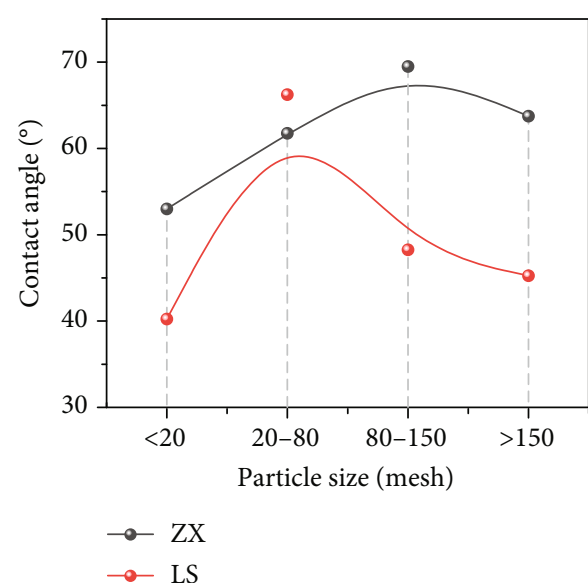

(a)

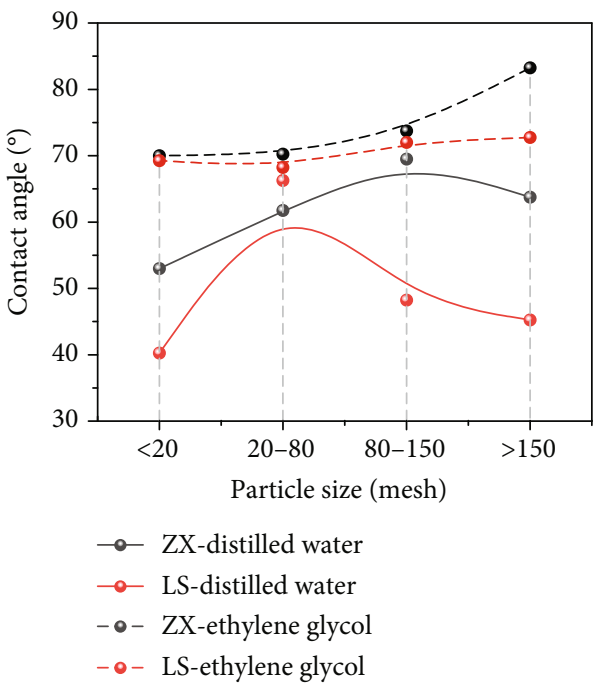

(c)

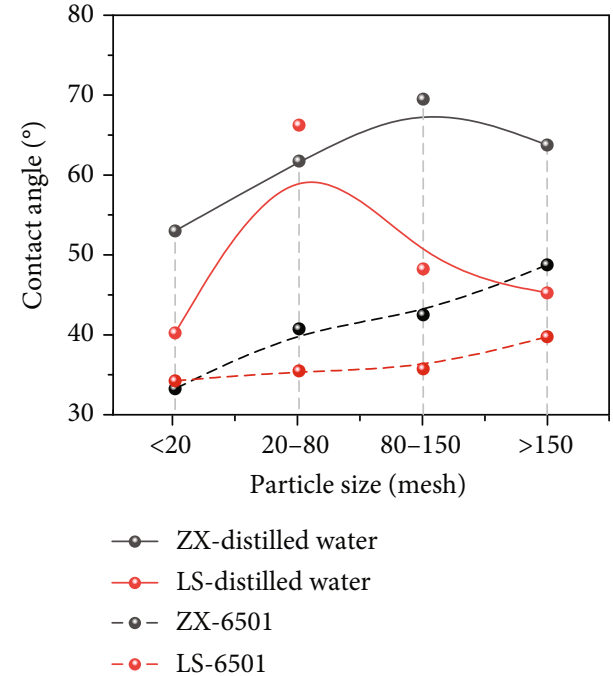

(b)

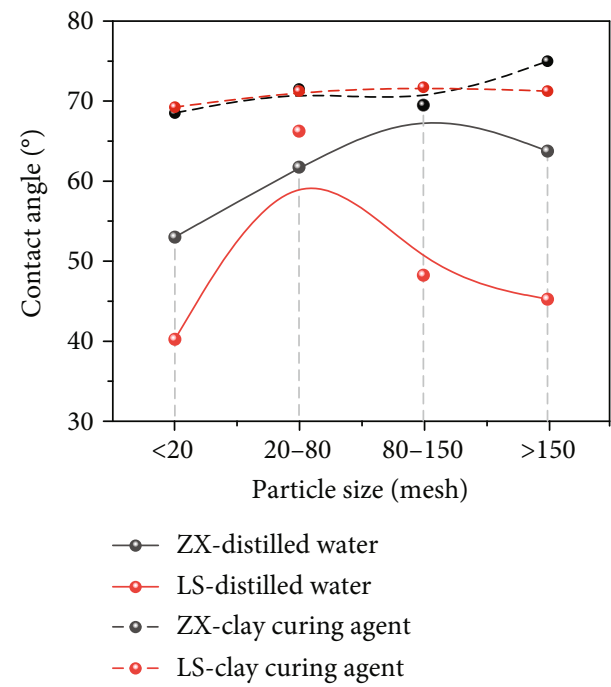

(d)

Figure 11: Contact angles of coal fines measured with different liquids ((a) distilled water, (b) 6501 solution, (c) glycol, and (d) clay curing agent).

wettability is. The contact angles of coal fines measured by distilled water are $40.25^{\circ}-69.5^{\circ}$, all less than $90^{\circ}$ (Figure 11(a)). The results show that the samples of each particle size of drilling cutting coal fines and bailing coal fines are hydrophilic, which is related to the fact that low-rank coal contains more polar oxygen-containing functional groups on the one hand, and more hydrophilic inorganic minerals in coal fines on the other hand. The contact angles of samples with different particle sizes of drilling cutting coal fines and bailing coal fines are $53^{\circ}-69.5^{\circ}$ and $40.25^{\circ}-60.25^{\circ}$, respectively. The contact angle of the latter is relatively small, and the wettability is better. Besides, the wettability is closely related to the particle size of coal fines. Generally speaking, the larger the particle size of coal fine particles, the better its wettability performance. At the same time, it is also affected by the material composition. The higher the mineral content, the better the wettability. For example, the contact angle of the particles with particle size $>150$ mesh should be the largest, but in fact this is not the case, because the coal fines with particle size $>150$ mesh have high ash content and many minerals, and the enhancement effect on wettability completely counteracts the negative effect of small particle size, but the contact angle is lower. Because of low ash content, high volatile content, and fixed carbon, the contact angle of 20-80 mesh coal fine particles is abnormally high under the double negative action of material composition and particle size, while the coal fine particles of 80-150 mesh and >150 mesh have higher wettability because of high ash content.

4.4.2. Wettability Modification. As a positive wetting agent of coal, 6501 can effectively reduce the contact angle of coalwater interface, and the change of contact angle before and after the action of 6501 is $5.50^{\circ}-30.75^{\circ}$. The wettability 
modification effect of drilling cutting coal fines is better than that of bailing coal fines. The change rate of contact angle of ZX sample is $23.53 \%$ and $33.85 \%$, and that of LS sample is $12.15 \%$ and $46.42 \%$. Except for $20-80$ mesh samples, the change rate of other ZX samples is higher than that of LS samples. The degree of modification is related to the mineral content and composition of coal fines. The worse the original wettability is, the greater the modification space is.

However, the wettability after the action of 6501 has a certain inheritance with the original wettability of the sample, that is, the original wettability is good, and the wettability after modification is also relatively good. The modification did not cause qualitative changes in the wettability of drill cutting coal fines and bailing coal fines (Figures 11(b) and 12). Secondly, the relationship between the modification strength of 6501 and the particle size of coal fines is not obvious, indicating that the particle size is not sensitive to the reaction of wetting agent. Ethylene glycol and clay curing agent are both negative wetting agents, both of which make the wettability of coal fines worse and the contact angle larger (Figures 11(c) and 11(d)). After the action of ethylene glycol, the contact angle of coal fines varies from $2^{\circ}$ to $29^{\circ}$, the change rate of contact angle of ZX sample is from $6.12 \%$ to $32.08 \%$, and that of LS sample is from $3.02 \%$ to $72.05 \%$. The wetting modification effect of ethylene glycol on coal fines is stronger (Figure 12). Because the original wettability of bailing coal fines is better, the contact angle is smaller, the space for hydrophobic transformation is larger, and it is more sensitive to the action of ethylene glycol, while the original wettability of drilling cutting coal fines is worse, the contact angle is relatively large, and the space for further hydrophobic transformation is limited. Therefore, the degree of sensitivity to the action of ethylene glycol is low. Moreover, the relationship between the modification effect of ethylene glycol and the particle size of coal fines is not obvious; but affected by its modification limit, the wettability of the modified samples tends to be the same, and the difference between them becomes smaller. The effect of clay curing agent is similar to that of ethylene glycol, and the contact angle of coal fines is increased by $0^{\circ}-29^{\circ}$. The change rate of ZX sample and LS sample is $0 \%-29.25 \%$ and $7.55 \%-72.05 \%$, respectively. The wettability of bailing coal fines is stronger than that of drilling cutting coal fines, and it is also affected by the hydrophobic transformation space of the sample (Figure 12). At the same time, the effect of particle size on the modification of clay curing agent is not obvious, and the wettability of the modified coal fine samples is similar to that of ethylene glycol. Compared with ethylene glycol, the modification effect of clay curing agent is slightly worse.

To sum up, the modification effect of surfactant on coal fines is mainly affected by the wettability and material composition of coal fines, the original wettability is poor, the modification effect of positive wetting agent is strong, the modification effect is good, and the wettability before and after modification has a certain inheritance, and the type and content of minerals may promote the modification of positive wetting agent to a certain extent. The better the original wettability is, the more significant the modification effect of negative wetting agent is, the modification effect is limited

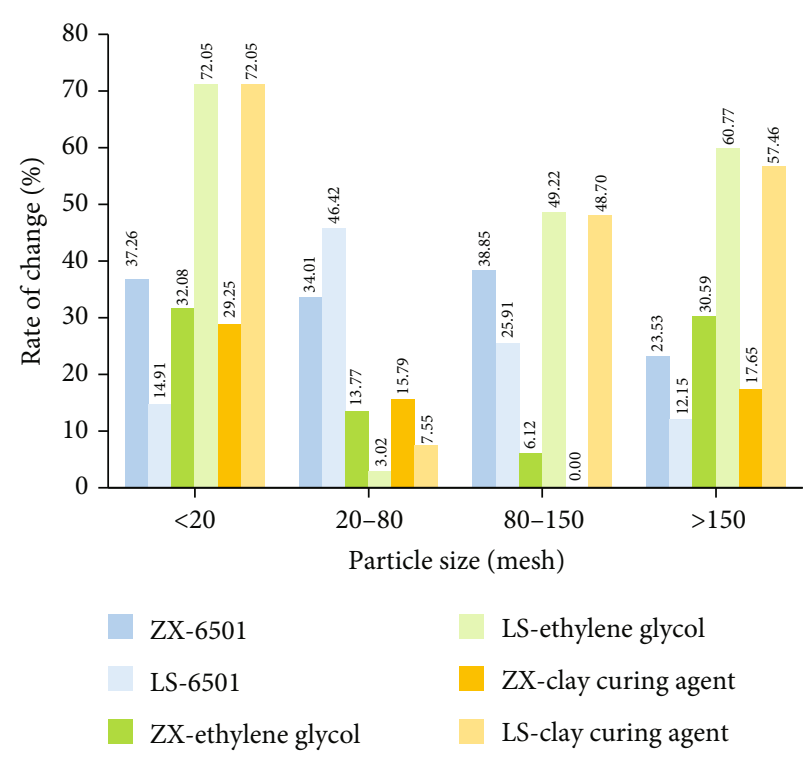

Figure 12: Modification effects of different active agents on coal fines.

by the reformable space, and the modification effect is limited, and the wettability of each coal fine sample tends to be the same after modification. Because the active agent acts mainly by adsorbing on the solid surface to form a hydrophilic layer or hydrophobic layer, the effect of coal fine particle size on the effect of surfactant is not obvious.

\subsection{Settleability}

4.5.1. Settling Rate. The settling rate of each sample is calculated through the static settling simulation experiment of coal fines. The results show that the settling rate of coal fines is between 6.97 and $47.60 \mathrm{~cm} / \mathrm{s}$. The largest settling rate is $<20$ mesh coal fines, and the smallest is $80-150$ mesh bailing coal fines (Figure 13(a)). Affected by the particle size, the settling rate of drilling cutting coal fines and bailing coal fines is an interval. When the size is less than 80 mesh, the settling rate of bailing coal fines is higher, and the sedimentation in water is faster. When it is more than 80 mesh, on the contrary, the settlement of drilling cutting coal fines is faster. Generally speaking, the settling rate of coal fines is closely related to particle size. The larger the particle size is, the greater the settling rate is, which is consistent with the traditional understanding of the settlement of solid particles in water. However, it is worth noting that when the particle size reaches more than 150 mesh, the settling rate does not continue to decrease, but increases against the trend, indicating that the main factors controlling the settling rate of extremely small coal fine particles have changed.

4.5.2. Influencing Factors. Due to the complexity of the material components of coal fines, including a variety of organic matter and inorganic minerals, there are differences in the density, wettability, and morphology of various components, which comprehensively affect the settleability of coal fine particles. The ash content of the samples with the particle size range of more than 150 mesh of drilling cutting coal fines and 


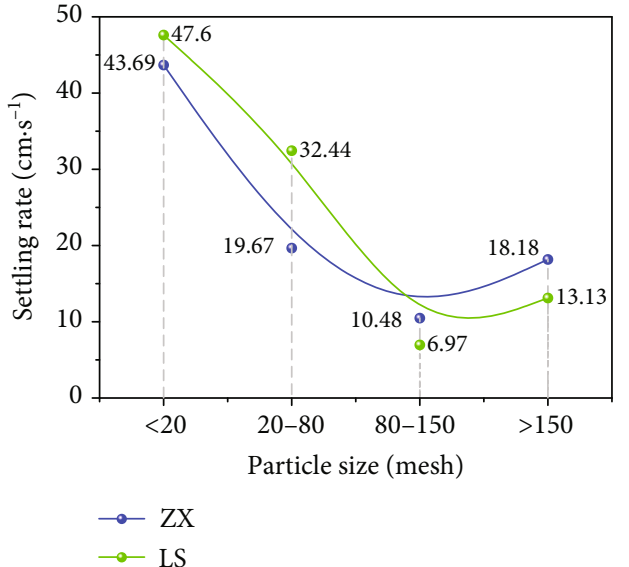

(a)

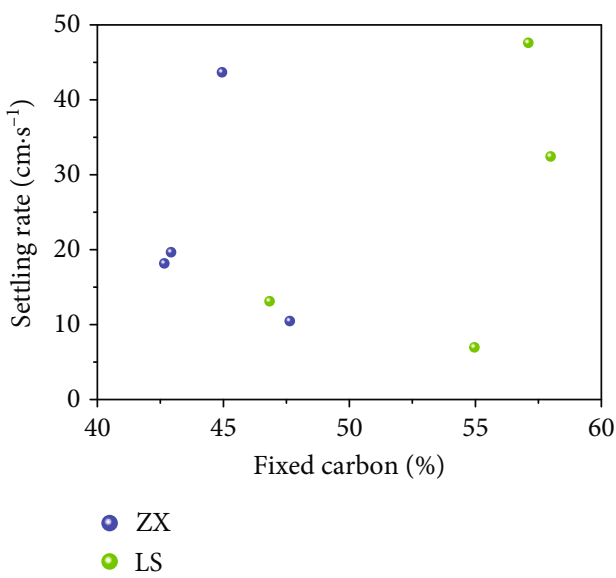

(c)

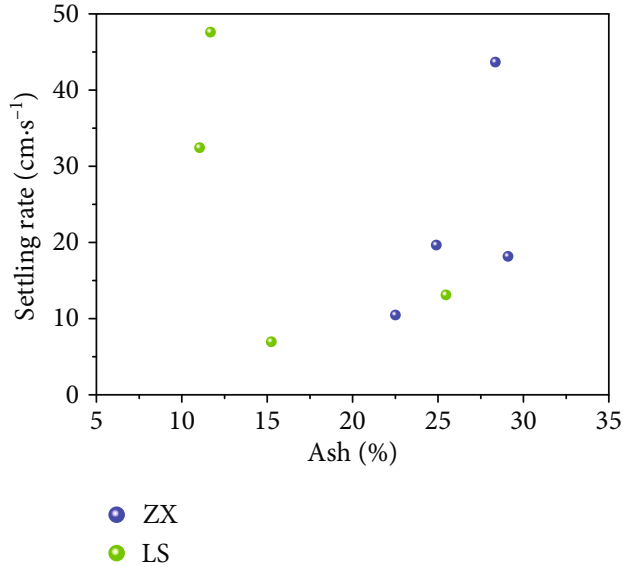

(b)

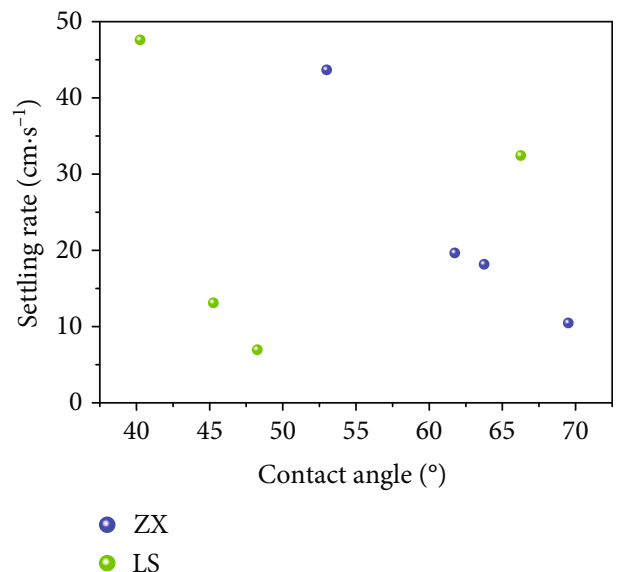

(d)

FIGURE 13: Settling rates of different coal fines and analysis of its influence factors ((a) different settling rates of coal fines, (b) relationship between settling rate of coal fines and ash content, (c) relationship between settling rate of coal fines and fixed carbon content, and (d) relationship between settling rate of coal fines and contact angle).

bailing coal fines is higher than that of other particle sizes, so it is inferred that the ash content is the main factor to control the settling rate of coal fines in this section. Compared with organic matter, the density of ash in coal is higher and the higher the ash content is, the greater the overall density of coal fine particles is and the faster the settling rate is. The analysis of the relationship between coal fine ash and settling rate shows that there is a better positive correlation between them (Figure 13(b)). Especially for drilling cutting coal fines and small particle size bailing coal fines, the relationship between ash content and settling rate is more obvious. On the contrary, the higher the fixed carbon content is, the more organic matter is contained in the coal fines, the overall specific gravity becomes smaller, and the settlement is slower, so there is a negative correlation between the settling rate of coal fines and the fixed carbon content (Figure 13(c)). Besides, the wettability of coal fines will also affect its settling rate. It is generally believed that the wettability of coal fines is good, which is conducive to the dispersion and suspension of coal fine particles in water and is not easy to settle [46]. However, the experimental results show that there is a negative correlation between the contact angle of coal fines and the settling rate (Figure 13(d)). That is to say, good wettability is conducive to the sedimentation of coal fines, which is inconsistent with previous research understanding, and it may be caused by the difference in particle size.

\section{Conclusions}

(1) The particle size of coal fines produced by coalbed methane wells in Binchang mining area is mainly micron, the particle size of drilling cuttings is mainly distributed in 20-150 mesh, and the bailing coal fines is mainly $>80$ mesh. The main type of laser particle size distribution curve of all kinds of coal fines is main-secondary bimodal type, the main peak particle size is between $30 \mu \mathrm{m}$ and $300 \mu \mathrm{m}$, and the main particle size is $1-400 \mu \mathrm{m}$. The particle size is as follows: drill cutting coal fines $>$ flowback coal fines $>$ bailing coal fines $>$ pipeline filter coal fines; bailing coal lower section $>$ middle section $>$ upper section

(2) The ash content of coal fines is higher than that of raw coal, drilling cutting coal fines is higher than 
bailing coal fines, and the fixed carbon of the former is lower than that of the latter, and the coarser the particle size of coal fines is, the lower the ash content is. Coal fines mainly contain kaolinite, illite, quartz, and other six kinds of minerals, drilling cutting coal fines are the most abundant, and bailing coal fines only contain illite and quartz

(3) The roundness of coal fine particles from good to bad is bailing coal fines, pipeline filter coal fines, flowback coal fines, and drilling cutting coal fines, drilling cutting coal fines are well sorted, the edge of particles is straight, neat, and smooth, and the sorting of bailing coal fines is poor. The edge of the particles is curved, staggered, and rough, and the morphological characteristics are closely related to the origin of coal fines

(4) The contact angle of coal fines is from $40.25^{\circ}$ to $69.5^{\circ}$, which is hydrophilic. The wettability of bailing coal fines is better than that of drilling cutting coal fines. The larger the particle size of coal fines is, the worse the wettability is. The worse the wettability is, the more obvious the modification effect of positive wetting agent is, the better the wettability is, and the better the modification effect of negative wetting agent is. The modification of surfactant has nothing to do with the particle size of coal fines but is closely related to organic components and minerals

(5) The static settling rate of coal fines is $6.97-47.60 \mathrm{~cm} / \mathrm{s}$. The larger the particle size of coal fines is, the greater the settling rate is. The higher the ash content of coal fines is, the lower the fixed carbon content is, and the faster the settling rate is. Taking 150 mesh as the demarcation point, the settling rate of large particle coal fines is mainly affected by particle size, and the settling rate of small particle coal fines is mainly affected by material composition

\section{Data Availability}

All data, models, and code generated or used during the study appear in the article.

\section{Conflicts of Interest}

The authors declared no potential conflicts of interest with respect to the research, authorship, and publication of this article.

\section{Acknowledgments}

This work is supported by the National Natural Science Foundation of China (Grant No. 41902175 and Grant No. 41972183), the Shanxi Province Science and Technology Major Special Funding Project (Grant No. 20201101002), the Shaanxi Province Natural Science Basic Research Program Funding Project (Grant No. 2019JQ-245), the Shaanxi Provincial Department of Education 2018 Special Scientific Research Project (18JK0518), the Open Project Funding Pro- ject of the Key Laboratory of Coal Resources Exploration and Comprehensive Utilization of the Ministry of Natural Resources (Grant No. KF2019-2), and the Projects Funded by China Postdoctoral Science Foundation (Grant No. 2019M653873XB). The authors also thank Editor and anonymous reviewers very much for valuable comments and suggestions that have greatly improved the manuscript.

\section{References}

[1] I. D. Palmer, Z. A. Moschovidis, and J. R. Cameron, "Coal failure and consequences for coalbed methane wells," in SPE Annual Technical Conference and Exhibition, Dallas, Texas, October 2005.

[2] Y. Wei, D. Cao, Y. Yuan et al., "Characteristics of pulverized coal during coalbed methane drainage in Hancheng block, Shaanxi Province, China," Energy Exploration \& Exploitation, vol. 31, no. 5, pp. 745-757, 2013.

[3] T. Bai, Z. Chen, S. M. Aminossadati, T. E. Rufford, and L. Li, "Experimental investigation on the impact of coal fines generation and migration on coal permeability," Journal of Petroleum Science and Engineering, vol. 159, pp. 257-266, 2017.

[4] Z. Guo, P. N. H. Vu, and F. Hussain, "A laboratory study of the effect of creep and fines migration on coal permeability during single-phase flow," International Journal of Coal Geology, vol. 200, pp. 61-76, 2018.

[5] S. Tao, D. Tang, H. Xu, and S. Li, "The influence of flow velocity on coal fines output and coal permeability in the Fukang Block, southern Junggar Basin, China," Scientific Reports, vol. 7, no. 1, article 14124, 2017.

[6] Z. Jian-xun and W. Youzhi, "Influence of tectonic action on coal petrography pore structure and CBM diffusion mode," Unconventional Oil \& Gas, vol. 2, no. 4, pp. 40-47+12, 2017.

[7] H. Zhang, Y. X. Mo, M. Sun, and X. Y. Wei, "Determination of the mineral distribution in pulverized coal using densitometry and laser particle sizing," Energy \& Fuels, vol. 19, no. 6, pp. 2261-2267, 2005.

[8] Y. Jintao, S. Jianbo, L. Gang, and X. Jie, "Literature review of permeability dynamic change law in CBM reservoir," Unconventional Oil \& Gas, vol. 2, no. 4, pp. 114-118, 2017.

[9] D. Cao, A. Wang, S. Ning et al., "Coalfield structure and structural controls on coal in China," International Journal of Coal Science \& Technology, vol. 7, no. 2, pp. 220-239, 2020.

[10] Z. Meng, J. Zhang, and R. Wang, "In-situ stress, pore pressure and stress-dependent permeability in the Southern Qinshui Basin," International Journal of Rock Mechanics and Mining Sciences, vol. 48, no. 1, pp. 122-131, 2011.

[11] I. Shovkun and D. N. Espinoza, "Coupled fluid flowgeomechanics simulation in stress-sensitive coal and shale reservoirs: impact of desorption-induced stresses, shear failure, and fines migration," Fuel, vol. 195, pp. 260-272, 2017.

[12] P. Bedrikovetsky, F. D. Siqueira, C. A. Furtado, and A. L. S. Souza, "Modified particle detachment model for colloidal transport in porous media," Transport in Porous Media, vol. 86, no. 2, pp. 353-383, 2011.

[13] S. Jinxing, Y. Shiyao, and S. Xianbo, "Study on velocity sensitivity damage mechanism and its proof test of coal reservoir," Coal Science and Technology, vol. 46, no. 6, pp. 173-177, 2018.

[14] W. Yingchun, L. Chao, C. Daiyong, Z. Aoxiang, Y. Zheng, and $\mathrm{X}$. Xianyue, "The output mechanism and control measures of 
the pulverized coal in coalbed methane development," Coal Geology \& Exploration, vol. 46, no. 2, pp. 68-73, 2018.

[15] Y. S. Zou, S. C. Zhang, and J. Zhang, "Experimental method to simulate coal fines migration and coal fines aggregation prevention in the hydraulic fracture," Transport in Porous Media, vol. 101, no. 1, pp. 17-34, 2014.

[16] X. Liu, C. Liu, and G. Liu, "Dynamic behavior of coalbed methane flow along the annulus of single-phase production," International Journal of Coal Science \& Technology, vol. 6, no. 4, pp. 547-555, 2019.

[17] C. Daiyong, Y. Yuan, W. Yingchun, L. Shenggui, L. Xiaoming, and W. Qingwei, "Comprehensive classification study of coal fines genetic mechanism and origin site," Coal Geology of China, vol. 24, no. 1, pp. 10-12, 2012.

[18] W. Haoqiang, P. Xiaolong, Z. Suyang, and F. Ning, "Research progress of coal fine formation, migration and control in CBM well," Reservoir Evaluation and Development, vol. 10, no. 4, pp. 70-80, 2020.

[19] Z. Junfang, W. Shengwei, Q. Yi et al., "Characteristics and origin of coal powder in coalbed methane well," Natural Gas Geoscience, vol. 24, no. 6, pp. 1316-1320, 2013.

[20] L. Shenggui, H. Aimei, S. Bo, and L. Huifang, "Coal powder concentration warning and control measure during CBM well drainage," Journal of China Coal Society, vol. 37, no. 1, pp. 8690, 2012

[21] Q. Yaoguang, Z. Fenna, L. Bing et al., "Calculation on discharge flow of pulverized coal in gas production channel for coalbed methane well," Journal of China Coal Society, vol. 38, no. 9, pp. 1627-1633, 2013.

[22] H. Fansheng, K. Yili, L. Xiangchen, Y. Lijun, and $\mathrm{X}$. Chengyuan, "Incipient motion mechanisms and control measures of coal fines during single-phase water flow in coalbed fractures," Acta Petrolei Sinica, vol. 38, no. 8, pp. 947-954, 2017.

[23] W. Hanxiang and L. Wenjian, "Discussion on formation mechanism of coal powder in coalbed methane well," China Coal, vol. 38, no. 2, pp. 95-97+105, 2012.

[24] X. Zhao, S. Liu, S. Sang et al., "Characteristics and generation mechanisms of coal fines in coalbed methane wells in the southern Qinshui Basin, China," Journal of Natural Gas Science \& Engineering, vol. 34, pp. 849-863, 2016.

[25] C. Zhenhong, W. Yibing, and S. Ping, "Destructive influences and effectively treatments of coal powder to high rank coalbed methane production," Journal of China Coal Society, vol. 34, no. 2, pp. 229-232, 2009.

[26] C. Daiyong, Y. Zheng, L. Xiaoming, W. Yingchun, H. Aimei, and S. Bo, "Rules of coal powder output under physical simulation experiments of single-phase water flow displacement," Journal of China Coal Society, vol. 38, no. 4, pp. 624-628, 2013.

[27] C. Jinbang, L. Pei, M. Dongmin, L. Zhi, Z. Ke, and M. Fanyuan, "Experiment study on migration law of pulverized coal in borehole of coalbed methane horizontal well," Coal Science and Technology, vol. 44, no. 5, pp. 74-78+176, 2016.

[28] L. Shenggui, H. Xiaohei, and L. Fanghui, "Production mechanism and control measures of coal powder in coalbed methane horizontal well," Journal of Liaoning University of Technology (Natural Science edition), vol. 30, no. 4, pp. 508-512, 2011.

[29] M. Tian, M. Dongmin, C. Yue et al., "Start-migration law of coal powder with different particle sizes under multi-phase flow conditions in coalbed methane wells," Coal Science and Technology, vol. 48, no. 5, pp. 188-196, 2020.
[30] C. Wenwen, W. Shengwei, Q. Yi et al., "Migration and control of coal powder in CBM well," Journal of China Coal Society, vol. 39, no. S2, pp. 416-421, 2014.

[31] Y. Yanhui, T. Dazhen, Y. Yanlei, C. Longwei, and T. Shu, "Influence on velocity sensitivity effect of coal reservoir to production law of pulverized coal and gas productivity," Coal Science and Technology, vol. 43, no. 2, pp. 96-99+103, 2015.

[32] W. Yingchun, C. Maolin, Z. Jin, M. Tao, and Y. Zheng, “Aggregation and sedimentation experiments of coal fines with different particle sizes during CBM development," Coal Geology \& Exploration, vol. 48, no. 5, pp. 40-47, 2020.

[33] C. Lihu, Z. Suian, S. Huining, B. Jianmei, W. Huan, and Z. Wei, "Coal dust migration and treatment for coalbed methane horizontal wells in Qinshui Basin," Oil Drilling and Production Technology, vol. 34, no. 4, pp. 93-95, 2012.

[34] Y. Wei, C. Li, D. Cao, A. Zhang, A. Wang, and X. Xiang, "New progress on the coal fines affecting the development of coalbed methane," Acta Geologica Sinica-English Edition, vol. 92, no. 5, pp. 2060-2062, 2018.

[35] X. Yaobo, "Research on the production rule and prevention method of pulverized coal in horizontal CBM well," Coal Geology \& Exploration, vol. 44, no. 1, pp. 43-46, 2016.

[36] W. Yingchun, L. Chao, C. Daiyong, H. Le, and Z. Aoxiang, "Experiment on screening dispersants of pulverized coal with different sizes in CBM well-washing technology," Journal of China Coal Society, vol. 42, no. 11, pp. 2908-2913, 2017.

[37] Y. Zheng, C. Daiyong, W. Yingchun, Z. Xiaoyu, Z. Aoxiang, and L. Xiang, "Comprehensive analysis of prevention and control measures for coal fines in coalbed methane production," Coal Science and Technology, vol. 43, no. 8, pp. 124-128 $+162,2015$.

[38] A. Zhang, D. Cao, Y. Wei, and T. E. Rufford, "Characterization of fines produced during drainage of coalbed methane reservoirs in the Linfen block, Ordos Basin," Energy Exploration \& Exploitation, vol. 38, no. 5, pp. 1664-1679, 2020.

[39] Z. Guo, F. Hussain, and Y. Cinar, "Permeability variation associated with fines production from anthracite coal during water injection," International Journal of Coal Geology, vol. 147-148, pp. 46-57, 2015.

[40] Y. Wei, C. Li, D. Cao, A. Wang, A. Zhang, and Z. Yao, "The effects of particle size and inorganic mineral content on fines migration in fracturing proppant during coalbed methane production," Journal of Petroleum Science and Engineering, vol. 182, p. 106355, 2019.

[41] Y. Liu, J. Liu, Q. Lyu, J. Zhu, and F. Pan, "Microstructure analysis of fluidized preheating pulverized coal under $\mathrm{O}_{2} / \mathrm{CO}_{2}$ atmospheres," Fuel, vol. 292, p. 120386, 2021.

[42] Y. Kuang, B. He, W. Tong, and C. Wang, "Flow and reaction characteristics at different oxygen concentrations and inlet velocities in pulverized coal MILD combustion," Journal of the Energy Institute, vol. 94, pp. 63-72, 2021.

[43] C. Niu, W. Xia, and Y. Peng, "Analysis of coal wettability by inverse gas chromatography and its guidance for coal flotation," Fuel, vol. 228, pp. 290-296, 2018.

[44] M. Pawlik, J. S. Laskowski, and F. Melo, "Effect of coal surface wettability on aggregation of fine coal particles," Coal Preparation, vol. 24, no. 5-6, pp. 233-248, 2004.

[45] J. Yan, L. Chen, and Z. Li, "Removal of fine particles from coal combustion in the combined effect of acoustic agglomeration and seed droplets with wetting agent," Fuel, vol. 165, pp. 316-323, 2016. 
[46] D. Junjun, L. Liantao, C. Jinbang et al., "Static settlement of different types of pulverized coal in CBM wells," Journal of China Coal Society, vol. 43, no. S1, pp. 203-209, 2018.

[47] L. Yabing, Q. Yong, W. Xing, D. Zhonghui, and M. Dongmin, "Geology and emission of mine gas in Binchang mining area with low rank coal and high mine gas," Journal of China Coal Society, vol. 44, no. 7, pp. 2151-2158, 2019.

[48] M. Dongmin, W. Chuantao, Y. Fu et al., "Mass transfer process of desorption of CBM in Dafosi coal reservoir," Journal of China Coal Society, vol. 43, no. S1, pp. 225-234, 2018.

[49] C. Yue, M. Dongmin, X. Yucheng, G. Chen, Y. Fu, and S. Kai, "Study on wettability and influencing factors of different macroscopic components in low rank coal," Coal Science and Technology, vol. 47, no. 9, pp. 97-104, 2019.

[50] M. Dongmin, W. Chuantao, X. Yucheng, Z. Jiarui, S. Kai, and $\mathrm{Y}$. $\mathrm{Fu}$, "Optimization program of fracturing parameters for coalbed methane wells in Dafosi Minefield," Journal of Xi'an University of Science and Technology, vol. 39, no. 2, pp. 8591, 2019.

[51] G. Chen and Y. ZHang, Atlas of Minerals Thermal Analysis, Power-Crystal Analysis and Phase Transition, Sichuan Science Technology Press, Chengdu, 1989. 